\section{rev Psi}

Revista de Psicología (UNLP)

https://revistas.unlp.edu.ar/revpsi

\title{
Posiciones docentes subjetivantes. El buen encuentro
}

\author{
Mariela Mansanel $\left.\right|^{1,2}$ \\ Correspondencia \\ marielamansanel@yahoo.com.ar
}

Filiaciones institucionales

${ }^{1} \mathrm{EEE} \mathrm{n}{ }^{\circ} 503-$ Trastornos Emocionales Severos $\quad{ }^{2}$ Instituto de Formación Docente ${ }^{\circ} 9$ (Argentina) (Argentina)

\section{Resumen}

En este trabajo se intenta reflexionar acerca de aquellas posiciones y miradas docentes subjetivantes que favorecen a los alumnos que presentan una dificultad en su estructuración subjetiva para que puedan transitar de mejor modo el espacio escolar y así realizar un óptimo aprovechamiento de la propuesta educativa.

\section{Palabras clave}

singularidad | inclusión | subjetividad | educación

Proceso editorial
$\begin{array}{ll}\text { Recibido } & \text { 1ra decisión } \\ 20 \text { ene. } 2020 & 7 \text { jun. } 2020 \\ \text { Aceptado } & \text { Publicado } \\ 23 \text { jun. 2021 } & \text { 26 jun. 2021 }\end{array}$

\section{Proceso editorial}

ISSN

2422-572X

Licencia

Licencia de Cultura Libre CC-BY 4.0

(Compartir - Adaptar - Atribuir)

Entidad editora

RevPsi es una publicación de la

Facultad de Psicología (Universidad

Nacional de La Plata, Argentina) 


\section{Posições de ensino subjetivadoras. 0 bom encontro}

\section{Resumo}

Neste trabalho tentamos refletir sobre aquelas posições e pontos de vista de ensino subjetivo que favorecem os alunos que apresentam uma dificuldade em sua estruturação subjetiva para que eles possam se movimentar melhor no espaço escolar e assim fazer o melhor uso da proposta educacional.

\section{Palavras-chave}

singularidade | inclusão | subjetividade | educação

\section{Teaching positions that subjectivise. The good encounter}

\section{Abstract}

The aim of this paper is to reflect on those subjective teaching positions and perspectives that favour students who present difficulties in their subjective structuring so that they can better navigate the school environment and thus make the best use of the educational proposal.

\section{Keywords}

singularity | inclusion | subjectivity | education 
El presente trabajo se fundamenta en la importancia de reflexionar sobre las prácticas en los ámbitos educativos para poder repensar cuáles son las posiciones, las miradas docentes que favorecen para que los alumnos con trastornos emocionales severos puedan realizar un aprovechamiento óptimo de la propuesta educativa.

Para el ámbito educativo es un desafío constante el trabajo con niños/as y adolescentes que presentan dificultades en su estructuración, lo que trae aparejado el reto de generar ámbitos de discusión, de problematización de la práctica donde se pongan en juego diferentes variables de análisis para encontrar posibles modos de abordaje. Es lo que intento realizar a lo largo de este escrito.

Se hace necesario definir desde qué lugar nos situaremos para pensar el vínculo educativo con alumnos que ponen de manifiesto diversas dificultades, resultado de alteraciones en su constitución subjetiva, con el propósito de poder reflexionar sobre aquellas prácticas e intervenciones docentes que pueda favorecer sus trayectorias educativas.

En múltiples observaciones realizadas en el contexto escolar se detectan posiciones docentes que no contemplan la singularidad de alumno, miradas estigmatizantes que cierran la posibilidad de que algo diferente se produzca, que obturan los avances pedagógicos y provocan crisis en los alumnos. Ante esto, se considera importante compartir experiencias, transmitir orientaciones, y generar reflexiones acerca de cuáles son las mejores posiciones docentes para establecer con estos sujetos un nuevo vínculo que sostenga y habilite la función educativa.

Para ello haré referencia a algunas viñetas, resultado de observaciones realizadas en el contexto escolar, referidas a niños con diagnósticos médicos (psicosis y TGD) que presentan obstáculos para emprender aprendizajes formales y que permitirán analizar las respuestas ofrecidas por los docentes.

\section{Viñetas}

Me acerco a un secundario para dar una serie de orientaciones para trabajar con un adolescente, al que llamaremos L. que, según el equipo de salud tratante, tiene un diagnóstico de psicosis. Los profesores del alumno inmediatamente preguntan: ¿cuál es el diagnóstico? Advierto cierta preocupación por el diagnóstico. Mi hipótesis acerca de esta preocupación tiene que ver con que es habitual, en el cuerpo docente, que aparezca la necesidad de encasillar, de etiquetar al alumno, como si ello les otorgase tranquilidad de que están preparados, teniendo la certeza de que es peligroso y que es por causa de tal o cual diagnóstico que el alumno no aprende. Respondo que no importa el diagnóstico y los invito pensar en L. y en su modo singular de aprender. Dicen que L. no aprende y que eso les preocupa. Pienso que L. no aprende como ellos quieren que aprenda. Pregunto si es el único alumno que no aprende. Se quedan callados, pensando y contestan "hay varios que tienen problema para aprender". Me dicen: "lo que pasa es que L. tiene un diagnóstico".

Mi posición docente, mi mirada sobre el alumno, obtura o favorece el aprendizaje. No 
todo depende del alumno y cuando un alumno no aprende debo analizar y reflexionar la acerca del vínculo docente- alumno. Y para ellos- pienso yo- el diagnóstico determina a L. ¡iYa está destinado a no aprender!! Ya no se apostará a este alumno, no se pensarán nuevas y diferentes estrategias. En tanto hay una tendencia a creer que nada se puede hacer para cambiar su condición, queda condenado, atado a un destino preestablecido por su diagnóstico. Abordar las problemáticas de la subjetivación y la formación educativa implica un accionar que es lo contrario a una objetivación $a$ priori, que clasifica y elide lo histórico y lo contextual.

Me acerco a un jardín a observar a un niño muy pequeño de tres años, que llamaremos M., que presenta un diagnóstico de TGD no especificado, según equipo de salud tratante. Lo observo en la clase de música. Me sorprende que la Seño, cuando reparte instrumentos, no le da a M. Tampoco lo hace cuando reparte hojas de revista. Hace dos meses que empezaron las clases y la Seño ya no apuesta a M., no lo registra, no lo piensa. M. no tiene un lugar y solo tiene 3 años.

Los niños pequeños están en un momento de estructuración subjetiva en donde todo es posible y por eso debemos bregar por aquellas posiciones que favorezcan la continuidad en la construcción de la subjetividad para que algo diferente pueda producirse, para que lo que no existe pueda darse y confiar en que algo se producirá. Es necesario operar a sobre los alumnos. Es necesario, como docente, acompañarlos para que anuden, hacer de andamiaje para que algo se construya del modo que ellos puedan.

"A mí no me prepararon para esto". Esta es una frase que escucho cada vez que me llaman para observar a un alumno. Y cada vez pienso y los hago pensar a los docentes de esos alumnos por los cuales me convocan. Justamente de eso se trata "no estar preparado" en el sentido de no tener una idea cerrada sobre algo, de poder crear teniendo en cuenta la singularidad de ese niño. Como docente ante un niño con alguna dificultad en su estructuración psíquica es importante que me vaya de la clase pensando sobre ese niño, pensando en su modo particular de aprender. Debo irme con una pregunta acerca de cómo aprende L., para construir la respuesta con él y con muchos otros que también están pensando en él. Estructuralmente, el vínculo educativo siempre "es del orden de lo particular, con cada sujeto es un vínculo nuevo que incluye sus transformaciones" (Tizio, 2001, p. 172). Este marco debe ser mantenido por el docente como lugar, como espacio necesario que permita alojar esa particularidad. Esto implica, por una parte, que el docente deba sostener y tolerar un cierto no saber: no saber sobre el sujeto, sus intereses, los tiempos de apropiación de lo que se trasmite. Por otra, que sea conocedor de teorías del campo de la pedagogía y de la psicopatología infanto-juvenil. Esto plantea un desafío. Es necesario, además, sostener el deseo de que algo diferente se produzca con ese niño, porque una posición docente de este tipo favorece a que se dé un encuentro con un niño que ha podido construir muy pocas herramientas para sostener un lazo con el otro, con 
todo lo que ello implica. Somos nosotros los que debemos generar las condiciones educativas para que el alumno aprenda. A L. hay que hacerle un lugar, porque primero, para poder establecer una situación pedagógica con L, me tengo que encontrar con él; L tiene que consentir conmigo, me tiene que dejar entrar. Para ello le tengo que hacer un lugar, tengo que armar con él aquello que es necesario que se construya para que advenga lo pedagógico, y que es primordial: que exista un sujeto. Hay que ir de a poco, hay que saber esperar, hay que pensar en los tiempos de L., hay que pensar en el modo de L., y eso es un descubrimiento. No hay recetas porque de eso se trata: de tener ganas de aprender, de tener el deseo de descubrir pudiendo mantenerse en el desafío aun cuando el alumno muchas veces no consienta.

Siempre se trata de pensar en lo singular de ese niño, entendiéndose lo singular como ese modo particular y propio de funcionamiento de habitar el espacio escolar, alejándose de las posturas que tienden al "para todos", a la normalización y el adiestramiento, en la medida en que estas posturas borran al sujeto, sabiendo que para que se dé el aprendizaje se trata justamente de lo contrario: buscar al sujeto, hallar lo que hay de singular en él, trabajar para que aparezca. Cuando uno va a este encuentro, el modo de ir debe ser sutil, cauto, sobre todo porque muchas veces estamos frente a un niño que no quiere o no puede "formar parte de". Hay que construir un amarre con el otro. Se trata de que este niño pueda tolerar lo mejor posible estar con los otros, pero no como nosotros queremos, sino como él pueda, teniendo en cuenta que la experiencia educativa no es sin el otro, en tanto aprender es un acto psíquico que se realiza en un vínculo con los otros humanos.

Es frecuente que a estos niños les lleve mucho tiempo familiarizarse con la institución, ya que desde la precariedad de su estructura tienen pocos recursos para tramitar los múltiples estímulos que se les presentan, así como presencia de los otros. Es por ello por lo que durante este tiempo tienen crisis, se quieren ir, golpean, se golpean... aquí es necesario esperar y respetar los tiempos de ese niño. Hay que acompañarlos a construir herramientas para encontrar un modo de estar con otros y este modo siempre es singular.

Muchos de estos niños tienen movimientos estereotipados, intereses restringidos. Se tratará de que mediante intervenciones se genere otra cosa donde el otro tenga lugar, favoreciendo que se establezca una relación de ida y vuelta, siempre en la medida de lo posible. Siempre se trata de que el alumno consienta. En ocasiones observamos niños desorganizados, con un mundo psíquico caótico, angustiante, sufriente, sin límites que los contengan. Aquí el trabajo es lograr que el niño consienta respecto a las normas. El límite siempre es necesario, debe estar porque ordena, acota el desborde. Pero en esta instancia es importante con estos niños buscar, no su acatamiento, sino su consentimiento, es decir que acepte de buen modo aquello que se le demanda.

Los niños que tienen dificultades en su estructuración psíquica necesitan de un otro alojador, de un otro flexible, que esté dispuesto a respetar su modo de aprender, que se le respete al igual que a otros niños porque todos los niños tienen su modo 
particular de transitar el aprendizaje. Tal como lo recuerda Tizio (2001), "el vínculo educativo habla del agente, del sujeto y del saber (...) el saber en juego es lo que define formalmente el vínculo educativo" (p. 172) y abre la dimensión del sujeto. La oferta educativa debe incluir "un vacío como lugar necesario que permita alojar la particularidad del sujeto y darle la posibilidad de hacer con los contenidos culturales" (p. 172). Es necesario tener en cuenta que lo subjetivo está entrelazado con lo cognitivo, lo cual hace que el aprendizaje de cada uno sea muy particular y singular.

En ese camino de descubrimiento de este modo de aprender se establecen diálogos con el campo de la salud donde se entrelazan saberes y surgen nuevos sentidos acerca de cómo aprende ese niño, acerca de su modo de transitar una institución educativa y su relación con los otros (su invención). Se establecen acuerdos siempre en pos de beneficiar la trayectoria educativa de ese niño.

Es la posición de no saber ya mencionada, la que instala la oferta educativa y la que nos permite aprender sobre ese modo singular que tiene el niño de soportar un mundo lleno de normas y de un montón de otros que le demandan. Nosotros como docentes debemos acompañarlos para que puedan soportar del mejor modo la escena docente, escena que no es sin el otro.

Todo niño se resiste a hacer lo que el Otro le pide e intenta hacer todo a su modo. Es el recurso de la palabra el que lo ayuda a resignar lo que quiere. El niño dice: "no quiero hacer los deberes" "por qué debo hacerlos", reniega, pero tramita la demanda del Otro y logra hacer la tarea. Cuando no se tiene el recurso de la palabra, ante la demanda del Otro el niño se muerde, muerde, golpea vidrios, llora, patea, golpea al otro. La demanda lo desorganiza porque no tiene recursos simbólicos para tramitarla. Su abordaje debe ser de lado, porque la demanda directa muchas veces los repliega. Sería como demandarles sin que se den cuenta.

Muchas veces se solicitan respuestas o recetas para el abordaje de estos niños. Pero con estos niños, como con ningún niño, no hay soluciones acabadas porque si las hubiera creeríamos entonces que ya lo sabemos todo y no podríamos seguir aprendiendo ni ajustarnos a cada uno de los niños. Como docentes debemos contemplar intervenciones pedagógicas dirigidas a favorecer la estructuración subjetiva, que le permitan al alumno devenir como sujeto, y así promover la construcción cognitiva.

Pensar la constitución de la subjetividad implica ubicar una encrucijada de determinaciones. Son los avatares y las vicisitudes posibles en el tránsito de la constitución subjetiva lo que hace imprescindible la creación de espacios de discusión y reflexión que nos permitan construir prácticas innovadoras, adecuadas, productoras de subjetividad. Se trata de instaurar miradas que contemplen múltiples dimensiones en el momento de pensar estrategias y abordajes, donde se den entrecruzamientos de saberes, como un proceso necesario para un abordaje integral. Es importante poder pensar, interrogar y observar la constitución de los niños como sujetos, y desde allí desafiar a una nueva configuración de las prácticas escolares y de las posiciones y decisiones de los educadores alineadas a las prácticas subjetivantes. 


\section{Referencias}

Aulagnier, P. (1975). La violencia de la interpretación. Amorrortu.

Bleichmar, S. (1993). La fundación de lo inconsciente. Amorrortu.

Carli, S. (1999). De la familia a la escuela. Infancia, socialización y subjetividad. Santillana.

Janin, B. (2011). El sufrimiento psíquico en los niños. Psicopatología infantil y constitución subjetiva. Noveduc.

Lacan, J. (2005). De los nombres del padre. Paidós.
Laurent, E. (2013). La batalla del autismo. De la clínica a la política. Grama.

Maleval J.C. (2011). El autista y su voz. Gredos.

Tendlarz, S. (2016). Clínica y la psicosis en la infancia. Colección Diva.

Tizio, H. (2001). La posición de los profesionales en los aparatos de gestión del síntoma. En H. Tizio (Coord), Reinventar el vínculo educativo: aportes de la pedagogía social y del psicoanálisis (pp. 165-182). Gedisa. 